\section{Quasi-Static Cyclic Response of Unidirectional Thin-Ply Hybrid Composites}

\author{
Putu Suwarta, ${ }^{1,}$, Gergely Czel $^{2}$, Mohamad Fotouhi ${ }^{3}$, Marco L. Longana ${ }^{4}$, Sutikno ${ }^{1}$, \\ Michael R. Wisnom ${ }^{4}$ \\ ${ }^{1}$ Department of Mechanical Engineering, Institut Teknologi Sepuluh Nopember, Surabaya 60111, Indonesia \\ ${ }^{2}$ Department of Polymer Engineering, Budapest University of Technology and Economics, Müegyetem rkp. 3, \\ $\mathrm{H}-1111$ Budapest, Hungary \\ ${ }^{3}$ James Watt School of Engineering, University of Glasgow, Glasgow, G12 8QQ, United Kingdom \\ ${ }^{4}$ Bristol Composites Institute (ACCIS), University of Bristol, BS8 1TR Bristol, United Kingdom \\ Received: 1 February 2021, Revised: 10 September 2021, Accepted: 11 September 2021
}

\begin{abstract}
Quasi-static cyclic loading of unidirectional (UD) thin-ply hybrid composites was conducted to assess the extent of stiffness loss with increasing applied strain. For this study, three types of hybrid configuration were examined: $\mathrm{SG}_{1} / \mathrm{MR}_{4}{ }_{1} / \mathrm{SG}_{1}, \mathrm{SG}_{1} / \mathrm{TR} 30_{1} / \mathrm{SG}_{1}, \mathrm{SG}_{1} / \mathrm{TR}_{2} 0_{2} / \mathrm{SG}_{1}$, where SG is a high strength glass fibre and MR40 is an intermediate modulus carbon fibre while TR30 is a standard modulus carbon fibre. The strain at first carbon ply failure and the knee point strain $\left(\varepsilon_{k}\right)$ for the $\mathrm{SG}_{1} / \mathrm{TR}_{30} / \mathrm{SG}_{1}$ hybrid is higher than for the $\mathrm{SG}_{1} / \mathrm{TR} 30_{2} / \mathrm{SG}_{1}$ hybrid. This is due to the 'hybrid effect' which provides a delay in damage initiation due to a constraint on broken carbon cluster development. For $\mathrm{SG}_{1} / \mathrm{MR}_{4} 0_{1} / \mathrm{SG}_{1}$ and $\mathrm{SG}_{1} / \mathrm{TR} 30_{2} / \mathrm{SG}_{1}$ configurations, the stiffness reduction over the course of loading was governed by fragmentation of the carbon plies and delamination between the carbon and glass plies. A smaller stiffness reduction for the $\mathrm{SG}_{1} / \mathrm{TR} 30_{1} / \mathrm{SG}_{1}$ configuration compared to the other hybrid configurations was observed with the fragmentation of the carbon ply as the main damage mechanism responsible for the reduction. With each loading cycle, there was a small amount of hysteresis and residual strain. The response of the UD thin-ply hybrid laminates are considered pseudo-ductile because the damage in the form of ply fragmentation and stable delamination, leads to gradual loss of stiffness. The stable delamination of this hybrid material is due to the low energy release rate of the thin carbon ply.
\end{abstract}

Keywords: Hybridisation, unidirectional, quasi-static cyclic loading, gradual failure

\section{Introduction}

Carbon fibre reinforced polymer composites (CFRP) are an attractive choice of material for the spacecraft and aerospace [1], land transportation [2] , sports equipment [3], renewable energy industries [4] as they exhibit desirable properties including low density coupled with high stiffness and strength, excellent fatigue and corrosion resistance [5], resulting in outstanding properties compared to traditional structural materials, such as aluminium or steel. However, the brittle nature of a composite structure hinders the design freedom and full exploitation of the outstanding mechanical properties.

Failure of this material type is usually sudden, without sufficient warning and little amount of residual load carrying capacity [6,7], which currently limits its application. To compensate for their brittle behaviour, conservative design limits and larger safety margins are usually applied for the composites. To overcome this problem, improvement to enhance the failure mode of fibre composites is needed. Creating pseudo-ductile or ductile fibre compos- ites with progressive failure mechanisms similar to metals' yielding and strain hardening assuring detectable warning and a wide margin between damage initiation and final failure is certainly of high interest. This could stretch the application of fibre composites towards high-volume, safety-critical applications such as in the automotive and construction industries.

The most straightforward method to impart ductility into fibre reinforced composite is to replace their brittle constituents (i.e. glass, carbon fibres, and thermosetting polymer resins) with new ductile materials. The recent focus has been on developing stiff and ductile fibres, because the mechanical properties of composites are fibre dominated. Allaer et al. [8] and Callens et al. [9-11], investigated the mechanical properties of various polymer matrix composites reinforced with an annealed stainless steel fibres (diameter of 5-100 $\mu \mathrm{m}$ ). The incorporated stainless steel fibres have a tensile failure strain up to $20 \%$ and stiffness of $193 \mathrm{GPa}$. Swolfs et al. [12] hybridised stainless steel fibres with self-reinforced polypropylene

"Corresponding author. Email: putu_suwarta@me.its.ac.id 
composites to investigate its behaviour under tensile loading. They reported an excellent toughness and ductile behaviour of fibre composites although the density of the obtained fibre composites was at least double that of carbon/epoxy, which hinders their suitability for lightweight applications.

Another simple approach to enhance the brittle failure mode of conventional fibre composites by potentially making it more gradual is by mixing different type of fibres either by comingling them [13-15] or creating ply-by-ply laminates [16-18]. Previous work on hybrids made of unidirectional (UD) layered glass/carbon has seen unstable delamination of the failed layers due to the high strain energy release rate [16]. Gradual failure and multiple cracking of carbon plies without unstable delamination in a UD layered glass/carbon hybrid incorporating 0.4 to $0.8 \mathrm{~mm}$ thick carbon layers was reported by Bunsell and Harris [18]. Despite the carbon thickness, the failure type is still gradual, which is believed to be a low strain energy release rate due to low carbon fibre failure strains $(0.26 \%)$, which was insufficient to drive delamination. The extend of delamination in a UD glass-carbon-glass sandwich laminates was reduced when including thinner central carbon layer as reported by Mander and Bader [19].

The application of a new emerging technology such as thin carbon prepregs into quasi-isotropic composites has shown to improve the mechanical properties under various loading conditions [20 22] towards higher failure strains due to suppression of matrix cracking and delamination. The lower energy release rates of thin carbon plies delay the propagation of inter-and intralaminar cracks, thus creates improved behaviour. Based on the reported work on hybrid and thin-ply prepregs, Czél et al. [23,24] examined the mechanical properties and failure behaviour of UD interlayer glass/carbon hybrids incorporating thin carbon plies under tensile loading. The glass-carbon hybrid composites show progressive damage mechanisms (i.e. fragmentation of carbon layers) and stable dispersed delamination after the first carbon layer fracture due to the low energy released [23] culminating into a pseudoductile failure response [25,26].

The so-called stable delamination is due to stable pull-out of the fragmented carbon layers from the undamaged glass layers, which prevents the catastrophic failure of the hybrid composite after the first carbon layer fracture. Appropriate material properties, and suitable values of relative thickness (i.e. thickness ratio of low strain material (LSM) to high strain material (HSM) and absolute thickness of low strain material (LSM) need to be selected, to achieve the desirable pseudo-ductile responses in hybrid composites under tensile loading, as shown by the design framework developed by Jalalvand et al. [27,-29].

Loading-unloading-reloading tensile test or widely known as quasi-static cyclic test has been performed by several researchers [30-33] to study the damage progression of fibre composites. The quasi-static cyclic response of UD polyolefin fibre reinforced cement composite was investigated by Keer [30]. The emerging multiple matrix cracking in the composite material during testing was responsible for the stiffness reduction. He explained that the relation between stiffness reduction with an increasing applied tensile strain for the composite material is well described by the Aveston-Cooper-Kelly (ACK) theory [34]. This theory assumes that when the matrix cracks, the additional load sustained by the fibre at the crack is transmitted back into the matrix by a constant interfacial shear stress, with the fibre slipping through the matrix. It should be noted that this theory is not well suited to describe the stiffness reduction behaviour of UD thin-ply hybrid composites because of the assumption of fibre slipping through the matrix does not occur in the UD thin-ply hybrid composite. The quasi-static cyclic response of two different types of fibre reinforced cement composite was also investigated by Keer [31]. He discover that the stiffness reduction rate of the composite material depends on the mechanical properties of the fibre. The stiffness reduction rate becomes slower when a high modulus polyethylene fibre is used as the reinforcement instead of a low modulus polypropylene fibre. This is due to the ability of the fibre to carry the load after matrix cracking under quasi-static cyclic loading.

The current paper differs from other work on quasistatic cyclic test of fibre composites e.g. [30,31] as fragmentation of the stiffer constituents and stable delamination never occurred on their specimens during quasi-static cyclic loading. Some initial results on the effect of gradual damage on the quasi-static cyclic behaviour of UD thinply carbon/glass hybrid composites have been presented by Wisnom et al. [33] but this paper is the first detailed characterisation of the quasi-static cyclic behaviour of UD thin ply carbon/glass hybrid composites. Three specimen configurations are investigated: (1) UD hybrid composite with a single layer of intermediate modulus (IM) carbon fibre, (2) UD hybrid composite with a single layer of standard modulus (SM) carbon fibre, (3) UD hybrid composite with double layers of standard modulus (SM) carbon fibre. These configurations were chosen based on the pseudoductile behaviour they have demonstrated in previous research [24].

\section{Experimental Method}

\subsection{Materials}

The thin-ply prepreg material being used for this study was carbon fibre reinforced polymer (CFRP) manufactured by SK Chemicals, South Korea. Two different types of thin carbon ply designated 'USN020A' and 'UIN050A' were used in the hybrid system. For the USN020A prepreg type, the code U, S, N, 020 and A indicate unidirectional fibres, standard fibre strength, no scrim, the fibre areal weight in $\mathrm{g} / \mathrm{m}^{2}$ and nominal resin weight content of 41\% [35] respectively. While for prepreg type UIN050A, the code U, A, and N have the same indication as for the previous USN020A prepreg type, as for I and 050 indicate intermediate modulus fibre and the fibre areal weight in $\mathrm{g} / \mathrm{m}^{2}$. The carbon fibres for USN020A was 
Table 1. Fibre properties of the applied UD prepregs (carbon fibre types: SM-standard modulus and IM- intermediate modulus).

\begin{tabular}{|c|c|c|c|c|c|c|}
\hline Fibre type & Manufacturer & $\begin{array}{l}\text { Tensile } \\
\text { modulus } \\
\text { [GPa] }\end{array}$ & $\begin{array}{c}\text { Tensile strain } \\
\text { to failure } \\
{[\%]}\end{array}$ & $\begin{array}{c}\text { Tensile } \\
\text { strength } \\
\text { [GPa] }\end{array}$ & $\begin{array}{l}\text { Density } \\
{\left[\mathrm{g} / \mathrm{cm}^{3}\right]}\end{array}$ & $\begin{array}{c}\text { CTE } \\
\text { (alpha) } \\
{[1 / \mathrm{K}]}\end{array}$ \\
\hline $\begin{array}{c}\text { Pyrofil } \\
\text { TR30 carbon }\end{array}$ & $\begin{array}{l}\text { Mitsubishi } \\
\text { Rayon }\end{array}$ & $234(\mathrm{SM})$ & $1.9[36]$ & 4.41 & 1.79 & $-4 \cdot\left(10^{-7}\right)$ \\
\hline $\begin{array}{c}\text { Pyrofil } \\
\text { MR40 carbon }\end{array}$ & $\begin{array}{l}\text { Mitsubishi } \\
\text { Rayon }\end{array}$ & 295 (IM) & 1.5 & 4.41 & 1.76 & $-1.1 \cdot\left(10^{-6}\right)$ \\
\hline $\begin{array}{l}\text { FliteStrand } \\
\text { SZT S-glass }\end{array}$ & $\begin{array}{l}\text { Owens } \\
\text { Corning }\end{array}$ & 88 & 5.5 & 4.8 to 5.1 & 2.45 & $2 \cdot\left(10^{-6}\right)$ \\
\hline
\end{tabular}

Table 2. Cured ply properties of the applied UD prepregs.

\begin{tabular}{ccccccc}
\hline $\begin{array}{c}\text { Prepreg } \\
\text { type }\end{array}$ & $\begin{array}{c}\text { Property } \\
\text { Unit }\end{array}$ & $\begin{array}{c}\text { Fibre mass } \\
\text { per unit area } \\
{\left[\mathrm{g} / \mathrm{m}^{2}\right]}\end{array}$ & $\begin{array}{c}\text { Cured ply } \\
\text { thickness } \\
{[\mathrm{mm}]}\end{array}$ & $\begin{array}{c}\text { Fibre volume } \\
\text { fraction } \\
{[\%]}\end{array}$ & $\begin{array}{c}\text { Initial elastic } \\
\text { modulus } \\
{[\mathrm{GPa}]}\end{array}$ & $\begin{array}{c}\text { Tensile strain } \\
\text { to failure } \\
{[\%]}\end{array}$ \\
\hline TR30 /epoxy & Average & $21.2[23]$ & $0.029[23]$ & $40.5[23]$ & $101.7^{a}[23]$ & $1.5^{a}[23]$ \\
& COV [\%] & $4.0[23]$ & - & - & $2.8[23]$ & $7.5[23]$ \\
MR40 /epoxy & Average & $50[37]$ & $0.061[37]$ & $45^{b}[37]$ & $134.6[37]$ & - \\
& COV [\%] & - & - & - & - & - \\
S-glass/epoxy & Average & $190[36]$ & $0.155[36]$ & $51^{b}[36]$ & $45.7[36]$ & $3.98[36]$ \\
& COV [\%] & - & - & - & $3.2[36]$ & $1.1[36]$ \\
\hline
\end{tabular}

${ }^{a}$ Measured on 16 ply UD laminates with $100 / 10 \mathrm{~mm}$ free length/width.

${ }^{b}$ Based on manufacturer's data.

a Mitsubishi Rayon TR30, classified as high strength, standard modulus and produced in 6000 filament tows [38] and for UIN050A, the fibres was a Mitsubishi rayon MR40, classified as intermediate modulus and produced in 12000 filament tows [38]. The matrix material was SK Chemicals semi-toughened epoxy, designated K50 [39]. For the high strain material, standard thickness S-glass/epoxy prepreg supplied by Hexcel was used, and the fibres was FliteStrand S ZT S-glass manufactured by Owens Corning [40]. The matrix material in the standard thickness S-glass/epoxy prepreg was the aerospace grade 913 (Hexcel). The material data for the fibres and prepregs are presented in Table 1 and 2 respectively. The good integrity of the hybrid laminates was confirmed during the test procedures and no layer separation was seen on crosssectional micrographs.

\subsection{Manufacturing Method}

The UD hybrid laminates were constructed by placing the $0^{\circ}$ plies on top of each other by using a clean, flat surface wooden plate in a temperature- and humiditycontrolled clean room. The plies were laid-up on top of a wooden plate to ensure the alignment of the $0^{\circ}$ fibres as the plate acts as a guideline. The layup sequence investigated in this work was $\left[\mathrm{SG} / \mathrm{C}_{n} / \mathrm{SG}\right.$ ], where $\mathrm{n}=1,2$, is the number of central carbon plies (C) with SG standing for S-glass. For the hybrid combination of S-glass/MR40 carbon, only a single ply of carbon was used while for S-glass/TR30 carbon, single and double plies of carbon were used. The finished laminates were then placed inside a vacuum bag and were then cured in an autoclave at the recommended cure temperature and pressure cycle for Hexcel 913 epoxy resin $\left(60 \mathrm{~min} @ 125{ }^{\circ} \mathrm{C}, 0.7 \mathrm{MPa}\right)$. The constituent prepregs were found to be compatible, even though the suppliers provided no details on the chemical formulation. End tabs with $1.6 \mathrm{~mm}$ thickness, made of glass/epoxy balanced fabric reinforced plates supplied by Heathcotes Co. Ltd. were bonded to the specimen using an Araldite 2014 epoxy adhesive supplied by Huntsman and cured for 60 min@ @ ${ }^{\circ} \mathrm{C}$ inside a fan convection oven. The aim of adding the end tabs was to protect the specimens from the high clamping force and avoid premature failure in the gripping region.

\subsection{Specimen Geometry}

In this study, the geometry of the UD hybrid specimens tested within the experimental part were UD, parallel edge tensile specimens with the following dimensions 240/160/20/h (mm)-overall length (L)/ $\mathrm{L}_{f}$ free length/Wwidth/h-variable thickness respectively (see Figure 1). The notation $\mathrm{t}_{c}$ and $\mathrm{t}_{g}$ in refers to the nominal thickness of carbon and glass layers respectively. 


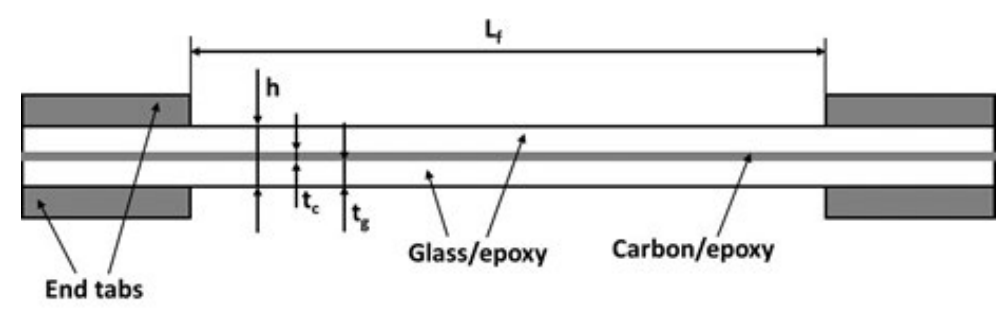

(a) Side view.

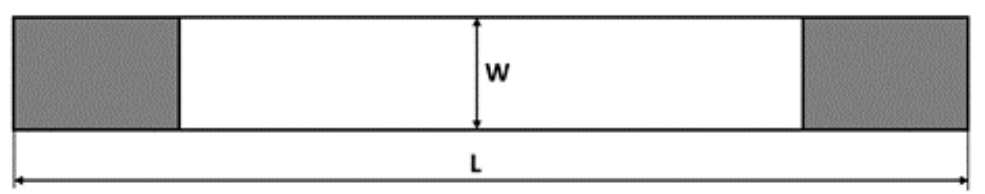

(b) Top view.

Figure 1. Schematic of thin-ply hybrid composite specimen.

\subsection{Mechanical Test Procedure}

Two types of mechanical testing were conducted on the UD thin-ply hybrid composites: static tensile and quasistatic cyclic loading. Both of those tests were performed at room temperature on a computer controlled Instron 8801 type $100 \mathrm{kN}$ rated universal hydraulic test machine with wedge type hydraulic grips. A $25 \mathrm{kN}$ rated load cell was used on the machine. For the static tests, the hybrid specimens were loaded in uniaxial tension under displacement control using a crosshead speed of $2 \mathrm{~mm} / \mathrm{min}$. For each hybrid configuration, three specimens were tested in static tensile loading. The quasi-static cyclic tests were conducted under displacement control at a cross-head speed of $2 \mathrm{~mm} / \mathrm{min}$ for both the loading and unloading phases, with immediate reloading. The number of quasistatic loading cycles was chosen based on the static tensile testing results of each hybrid configuration. A sufficient number of cycles was chosen to be able to study the effect of damage development on the load carrying capacity of the UD thin-ply hybrid composites. For the composites with one ply and two plies of TR 30, seven cycles were chosen, each with a certain displacement limit, after which the load returns to zero. The chosen displacements with their corresponding nominal laminate strains in brackets for thin-ply hybrid composites with 1 ply and 2 plies of TR30 were: $2.5 \mathrm{~mm}(1.56 \%), 3 \mathrm{~mm}(1.87 \%), 3.5 \mathrm{~mm}(2.18 \%)$, $4 \mathrm{~mm}(2.5 \%), 4.5 \mathrm{~mm}(2.81 \%), 5 \mathrm{~mm}$ (3.12\%), 5.65 $\mathrm{mm}(3.53 \%)$. For the other hybrid composite materials with 1 ply of MR 40 carbon fibre, the chosen displacements with their corresponding laminate strains in brackets were: $2.5 \mathrm{~mm}$ (1.56\%), $3 \mathrm{~mm}$ (1.87\%), $3.5 \mathrm{~mm}$ (2.18\%), $4 \mathrm{~mm}$ (2.5\%), $4.5 \mathrm{~mm}(2.81 \%), 5 \mathrm{~mm}$ (3.12\%), $5.5 \mathrm{~mm}$ (3.43\%). For each type of hybrid, three specimens were tested. To measure the strains with a nominal gauge length of 130 $\mathrm{mm}$, an Imetrum video gauge system with 5 Megapixel resolution was used and it allows a precision measurement down to $0.01 \%$ strain. The video gauge records with a speed of 17 frames per second. Videos recorded by the video gauge camera were kept for studying the damage development.

\subsection{Delamination Area Measurement Technique}

Typical damage development found during static tensile loading was fragmentation of the carbon/epoxy ply followed by delamination between the fragmented ply and glass/epoxy ply, as reported by Czél et al. [23]. Due to the translucent nature of the glass/epoxy ply on the outside of the hybrid laminate, it was possible to detect the delamination surrounding the fragmented carbon ply [23]. The growth of delamination area will be used as a measure of damage during quasi-static cyclic loading and its correlation with the load carrying capacity of UD thin-ply hybrid composites will be deduced. The delamination area was measured from the images collected by the video gauge using an in-house developed MATLAB code. The images, acquired in grayscale by the video extensometer system (Figure 23), are imported into MATLAB and cropped to cover only the specimen gauge length (Figure 2p). Finally, they are converted into binary black and white images using a predefined threshold (Figure 2k). The delaminated area was calculated by counting the white pixels and it was then compared against the total surface area to express it in terms of \% area. The four white dots shown in Figure 2 a were used to track the uniaxial strain using the video gauge system during the static loading. It should be noted from Figure $2 \mathrm{a}$ that well bonded areas appear black and the locally delaminated areas just around the cracks in the carbon ply are visible as the lighter areas due to the translucent nature of the glass/epoxy outer ply of the hybrid laminate. 


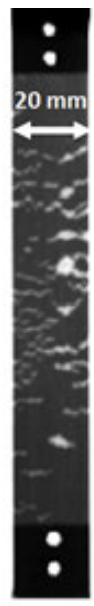

(a) Video gauge image.

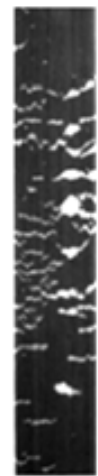

(b) Cropped gray scale image.

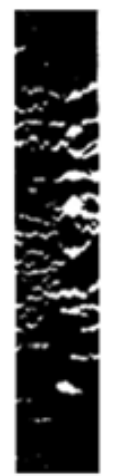

(c) Black and white image.

Figure 2. Image conversion process to determine the delamination area.

\section{Results and Discussion}

\subsection{Static loading response}

Figure 3 shows the stress-strain curves of the hybrids with initial linear elastic behaviour followed by non-linearity and a plateau for the $\mathrm{SG}_{1} / \mathrm{TR}_{3} 0_{2} / \mathrm{SG}_{1}$ and $\mathrm{SG}_{1} / \mathrm{MR}_{40} / \mathrm{SG}_{1}$ configurations. For the $\mathrm{SG}_{1} / \mathrm{TR} 30_{1} / \mathrm{SG}_{1}$ hybrids, there is a reduced slope after the non-linearity point. The configurations of the tested specimens are given in Table 3 along with their calculated mode II energy release rate at the expected failure strain of the carbon fibres $(\varepsilon)$. The equation to calculate the energy release rate is adopted from the work by Czél et al. [23] and it is written in terms of the overall applied strain $\varepsilon$ in Equation 1.

$$
G=\frac{\varepsilon^{2} E_{c} t_{c}\left(E_{g}\left(h-t_{c}\right)+E_{c} t_{c}\right)}{4 E_{g}\left(h-t_{c}\right)}
$$

The assumption for the energy release rate in Equation 1 is that the hybrid laminate loses the contribution from the carbon ply after the low strain ply fractures and delaminates from the laminate. This a reasonable assumption, since after the low strain ply fractures and delaminates, it does not contribute anymore to carrying load. The notation $\mathrm{g}$ and $\mathrm{c}$ in Equation 1, refers to glass/epoxy and carbon/epoxy respectively while $\mathrm{E}, \mathrm{h}$, and $\mathrm{t}$ are the material modulus, total laminate thickness and thickness of each ply. The calculated energy release rates shown in Table 3 for the three configurations are all lower than the fracture toughness (GIIC) of the glass/carbon composites, $1.1 \mathrm{~N} / \mathrm{mm}$ [23], which has been measured by Czel et al. [23] on a similar hybrid specimens but with a cut through the entire carbon layer across the width. This indicates that after the first fracture of the carbon ply, unstable delamination and pull-out of the central carbon ply is not expected in these specimen types.

The stress-strain response of the hybrid configurations shown in Figure 3, indicates different responses be- tween the hybrids comprising high strength (standard modulus) TR30 carbon plies with that comprising intermediate modulus MR 40 carbon plies. The damage mechanism for $\mathrm{SG}_{1} / \mathrm{TR}_{3} 0_{1} / \mathrm{SG}_{1}$ was observed as a dispersed fragmentation dominated failure, where damage in the form of short cracks develops in parallel across the specimen width. The fragmentation itself, appeared in the carbon ply between the knee transition points $(2.19 \%$ and $2.50 \%$ ). Due to the translucent glass ply, the gradual crack development was visible during tensile loading and reached saturation at $2.50 \%$. Between the knee transition points, there is a reduced of slope from the initial linear elastic region and smooth transition due to the damage mechanisms observed. After the second saturation point $(2.50 \%)$, the stress rises because the tensile machine still imposes a load on the hybrid specimen and the additional load is mainly carried by the glass plies (this phenomenon is also relevant for the $\mathrm{SG}_{1} / \mathrm{MR}_{40} / \mathrm{SG}_{1}$ and $\mathrm{SG}_{1} / \mathrm{TR}_{2} \mathrm{O}_{2} / \mathrm{SG}_{1}$ configurations). The explanation behind the gradual failure in $\mathrm{SG}_{1} / \mathrm{TR}_{3} \mathrm{O}_{1} / \mathrm{SG}_{1}$ is the low GII, as shown in Table 3, for this configuration due to the very low carbon ply thickness.

A favourable pseudo-ductile response was also obtained for the SG1/TR302/SG1configuration, displaying two pronounced knee transition points $(1.90 \%$ and $2.76 \%)$. The first knee transition point $(1.90 \%)$ referred to as $\varepsilon_{l}$, is where the fragmentation of the carbon/epoxy ply becomes established [41], and from $\varepsilon_{l}$, gradual damage development in the form of fragmentation and dispersed delamination appears in the specimen until it saturates at $2.76 \%$. Contrary to the previous hybrid configuration with a single TR30 carbon ply which has short cracks, the fragmentation in $\mathrm{SG}_{1} / \mathrm{TR} 30_{2} / \mathrm{SG}_{1}$ consisted of long and relatively straight cracks across the whole specimen width followed by stable pull-out of the fragmented carbon ply. Because of carbon ply fragmentation and dispersed delamination, a wide plateau between the first knee point strain $(1.90 \%)$ and second knee point strain $(2.76 \%)$ can be observed in this configuration, thus providing enough 
Table 3. Specimen types tested within the present study (Specimen type designation: SG-S Glass, C- Carbon, with numbers corresponding to the number of constituents prepreg ply, Carbon types: SM-standard modulus, IM-intermediate modulus).

\begin{tabular}{|c|c|c|c|}
\hline Spec. Type & $\begin{array}{c}\text { Carbon fibre type } \\
-\end{array}$ & $\begin{array}{l}\text { Nominal thickness } \\
\qquad(\mathrm{mm})\end{array}$ & $\begin{array}{l}\text { Mode II energy release rate at } \\
\text { the failure strain of the carbon ply } \\
(\mathrm{N} / \mathrm{mm})\end{array}$ \\
\hline SG1/MR401/SG1 & IM & 0.371 & 0.736 at $1.50 \%$ \\
\hline SG1/TR301/SG1 & SM & 0.339 & 0.322 at $1.90 \%$ \\
\hline SG1/TR302/SG1 & SM & 0.368 & 0.715 at $1.90 \%$ \\
\hline
\end{tabular}

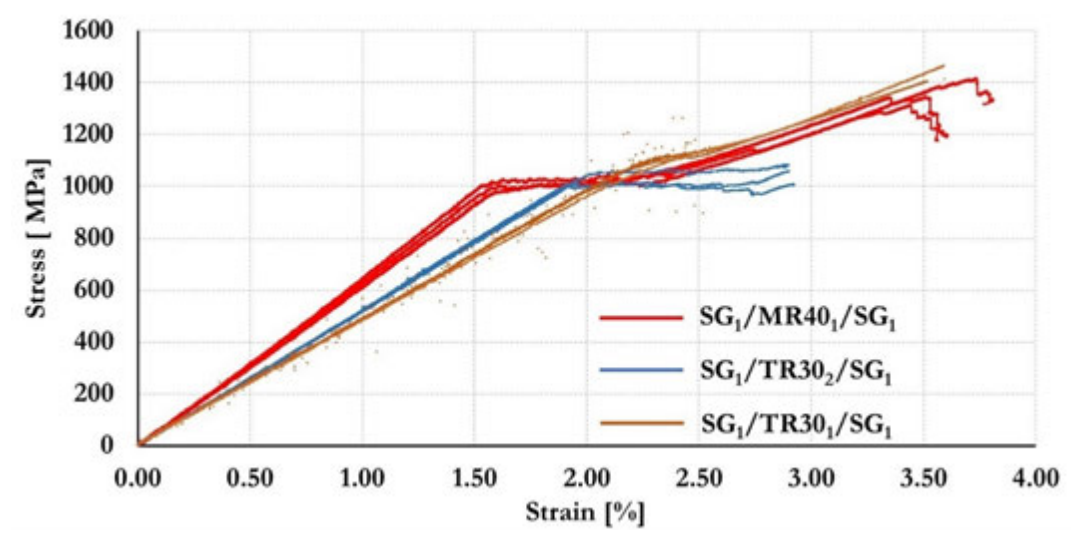

Figure 3. Stress-strain curves of various S-glass/high strength carbon hybrid. The outlier dots are the noise coming from the video gauge system.

strain margin before the final failure event. After careful examination of a typical damaged $\mathrm{SG}_{1} / \mathrm{TR} \mathrm{O}_{2} / \mathrm{SG}_{1}$ hybrid specimen when the test was interrupted at $2.76 \%$ strain, it can be concluded that the damaged pattern (fragmentation, delamination and intact carbon ply), is identical on the front and back face of the specimen as shown in Figure 4. The cracks shown in Figure 4 looks like a stair-shaped tortuous path across the whole width of the specimen. The variation of fibre strength results in distributed fibre breaks at random locations rather than cumulatively at the site of the initial break which creates a tortuous crack path [42]. As the fibre breaks, the overload in the adjacent fibre is redistributed, and when it exceeds the strength of a weak fibre segment, the fibre will fracture and serve as an initiation point for the next fibre failure. It is also expected that an identical damage pattern on both sides is present for $\mathrm{SG}_{1} / \mathrm{TR} 30_{1} / \mathrm{SG}_{1}$ and $\mathrm{SG}_{1} / \mathrm{MR}{ }_{1} / \mathrm{SG}_{1}$ hybrid configurations providing that there is marginal thickness variations across the width.

The hybrid with $\mathrm{SG}_{1} / \mathrm{MR} 40_{1} / \mathrm{SG}_{1}$ configuration also displays favourable pseudo-ductile failure behaviour as shown in Figure 3, with two obvious transition points $(1.53 \%$ and $2.31 \%)$. Multiple fragmentations and dispersed delamination also appear in this hybrid configuration contributing to the failure type and a plateau between the first knee point strain (1.53\%) and second knee point strain $(2.31 \%)$. The type of damage observed in $\mathrm{SG}_{1} / \mathrm{MR}_{4} \mathrm{O}_{1} / \mathrm{SG}_{1}$ was well distributed multiple crack formation (fragmentation) across the specimen's surface area.

All three hybrid configurations display pseudoductile response during static tensile loading with a noticeable difference in their first carbon strain to failure and knee-point strain where the fragmentation of the carbon ply has been established. The tensile results summary for the investigated hybrid configurations is shown in Table 4. Comparing the initial modulus of glass/epoxy ply in Table 2 with the that of hybrid configuration in Table 4 it is noticed that there is a modulus increase of $10.5 \%$, $19.3 \%$, and $38.2 \%$ for $\mathrm{SG}_{1} / \mathrm{TR}_{3} 0_{1} / \mathrm{SG}_{1}, \mathrm{SG} 1 / \mathrm{TR} 30_{2} / \mathrm{SG}_{1}$, $\mathrm{SG}_{1} / \mathrm{MR} 40_{1} / \mathrm{SG}_{1}$ respectively. Because the tensile test results are affected by the small thermal residual strains arising from the mismatch in the coefficient of thermal expansion between the glass and carbon layers, the strains shown in Table 4 have been corrected for the elastic thermal residual strain in the $0^{\circ}$. The elastic thermal strains were calculated from the equilibrium-force state between the carbon/epoxy and glass/epoxy layers by assuming constant strain through the thickness and a $100{ }^{\circ} \mathrm{C}$ temperature difference from the cure temperature to room temperature. The elastic thermal residual strain in the transverse direction is not taken into account in this work since the fibre in the hyrid laminate is in the $0^{\circ}$ direction and the load is mainly carried by the fibre. 
Table 4. Tensile results summary of the specimen types tested (Numbers in brackets indicates the coefficient of variation in [relative \%]).

\begin{tabular}{lcccccc}
\hline Spec. Type & $\begin{array}{c}\text { No. of } \\
\text { specimens }\end{array}$ & $\begin{array}{c}\text { Initial elastic } \\
\text { modulus } \\
{[\mathrm{GPa}]}\end{array}$ & $\begin{array}{c}\text { Strain at first } \\
\text { carbon ply failure } \\
{[\%]}\end{array}$ & $\begin{array}{c}\text { Strain at } \\
\text { knee point } \\
\varepsilon_{k} \\
{[\%]}\end{array}$ & $\begin{array}{c}\text { Stress at } \\
\text { knee point } \\
\sigma_{k} \\
{[\mathrm{MPa}]}\end{array}$ & $\begin{array}{c}\text { Pseudo- } \\
\text { ductile } \\
\varepsilon_{p d} \\
{[\%]}\end{array}$ \\
\hline SG1/MR401/SG1 & \multirow{2}{*}{3} & 63.11 & $1.53(2.4)$ & 1.55 & 983.9 & $1.19(12.40)$ \\
& & -2.3 & & -1.3 & -2.6 & - \\
SG1/TR301/SG1 & \multirow{2}{*}{3} & 48.91 & $2.13(2.5)$ & 2.19 & 1106.5 & -1.4 \\
& & -2.1 & & -3.1 & - \\
SG1/TR302/SG1 & \multirow{2}{*}{3} & 56.52 & \multirow{2}{*}{$1.85(2.2)$} & -1.9 & 1074.2 & -4 \\
\hline
\end{tabular}

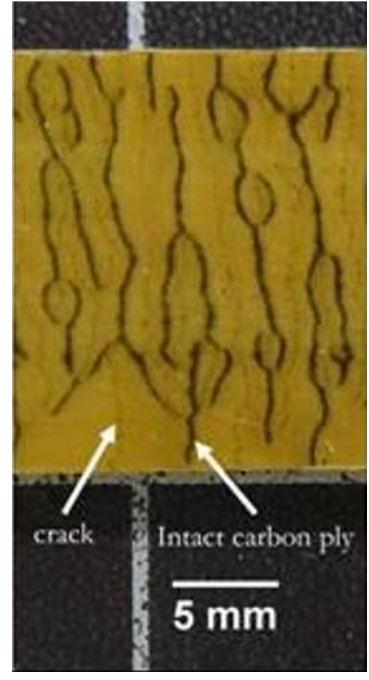

(a) Front face.

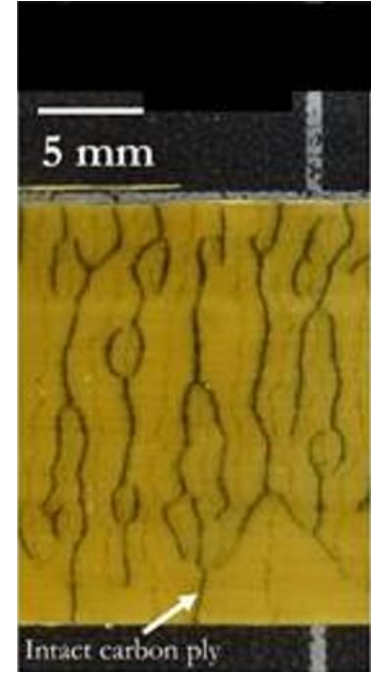

(b) Back face.

Figure 4. Identical damage pattern of SG1/TR302/SG1 hybrid specimen at $2.76 \%$ strain. The shape of the intact carbon ply is identical on both sides.

The calculated residual elastic strains in the carbon for the presented hybrid configuration are $-0.0224 \%$, $0.0261 \%,-0.0266 \%$ for $\mathrm{SG}_{1} / \mathrm{TR} 30_{2} / \mathrm{SG}_{1}, \mathrm{SG}_{1} / \mathrm{TR} 30_{1} / \mathrm{SG}_{1}$, $\mathrm{SG}_{1} / \mathrm{MR}_{40} / \mathrm{SG}_{1}$ respectively and this has been accounted for in the values in Table 4 for the strain at first carbon layer failure and at the knee-point strain.

The knee point stress $\left(\sigma_{k}\right)$ and strain $\left(\varepsilon_{k}\right)$ are found from the intersection of lines fitted to the initial linear (red line) and plateau (green line) parts of the stressstrain curves. For the second knee, the transition strain $\left(\varepsilon_{s}\right)$, is determined by the intersection of lines fitted to the plateau (green line) and the second rising part (blue line) of the stress-strain curves, as shown in Figure 5 .

It was possible to measure the first carbon fracture strain in the hybrid specimens from the recorded video gauge instrument as the first carbon crack is visible due to the translucent nature of the glass ply. As noted from Table 4, the strain at first carbon ply failure and knee point strain $\left(\varepsilon_{k}\right)$ for the $\mathrm{SG}_{1} / \mathrm{TR} 30_{1} / \mathrm{SG}_{1}$ hybrid is higher than for the $\mathrm{SG}_{1} / \mathrm{TR} 30_{2} / \mathrm{SG}_{1}$ hybrid. This is due to the 'hybrid effect' which provides a delay of damage initiation due to a restraint on broken carbon cluster development [41]. For the thinner hybrid with a single carbon ply, the fibre failure and fragmentation appear at a slightly higher strain because of the limited number of fibres through the thickness of the ply inhibiting formation of a critical cluster [41].

As shown in Figure 5 , the pseudo-ductile strain $\left(\varepsilon_{p d}\right)$ is defined between the strain of a point on the initial linear elastic line and the strain at the failure stress. The pseudoductile strain for $\mathrm{SG}_{1} / \mathrm{TR} 30_{1} / \mathrm{SG}_{1}$ and $\mathrm{SG}_{1} / \mathrm{TR} 3 \mathrm{O}_{2} / \mathrm{SG}_{1}$ hybrid configurations were not given in Table 4, because the testing was stopped before the final glass failure took place. Although the method in Figure 5 is shown for the $\left(\mathrm{SG}_{1} / \mathrm{MR} 40_{1} / \mathrm{SG}_{1}\right)$ configuration, it could also be applied to the other hybrid configurations. 


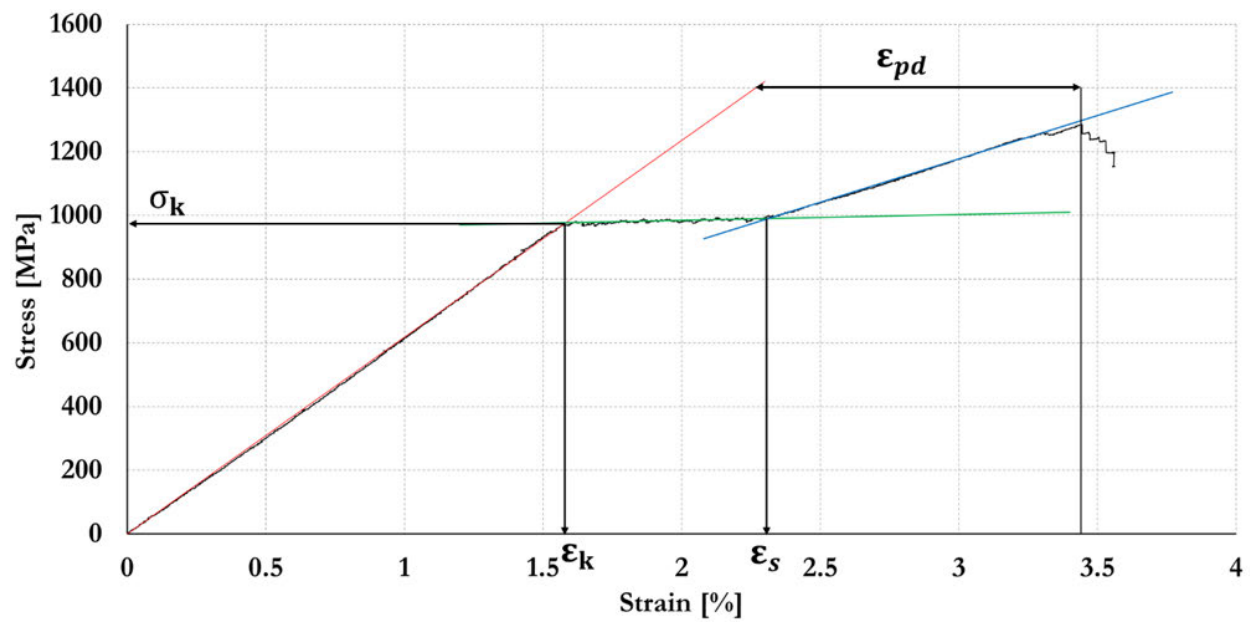

Figure 5. Method to determine knee point stress $\left(\sigma_{k}\right)$ and strain $\left(\varepsilon_{k}\right)$, second knee transition strain $\left(\varepsilon_{s}\right)$ and pseudo-ductile strain $\left(\varepsilon_{p d}\right)$ for a typical pseudo-ductile response of $\left(\mathrm{SG}_{1} / \mathrm{MR}_{4} 0_{1} / \mathrm{SG}_{1}\right)$.

\subsection{Quasi-static cyclic loading response}

\subsection{1. $\left[\mathrm{SG}_{1} / \mathrm{MR} 40_{1} / \mathrm{SG}_{1}\right]$ response}

The typical loading-unloading behaviour for an $\left[\mathrm{SG}_{1} / \mathrm{MR} 40_{1} / \mathrm{SG}_{1}\right]$ specimen is presented in Figure 6 , The cyclic responses show initial linear behaviour followed by non-linear behaviour and an increase of stress at higher strains after saturation of fragmentation. The notation from 1 until 6 in Figure 6 refers to the following peak strains: $1.45 \%, 1.82 \%, 2.17 \%, 2.45 \%, 2.77 \%, 3.05 \%$ respectively, from which the specimen was unloaded and subsequently reloaded.

During the first displacement loading, there was an initial linear response, and the subsequent unloading followed almost the same path because the damage threshold was not exceeded. The second loading trajectory overlaid the first but went beyond the initial failure strain of the carbon into the plateau region of the stress-strain response. The damage mechanism of the $\left[\mathrm{SG}_{1} / \mathrm{MR}_{4} \mathrm{O}_{1} / \mathrm{SG}_{1}\right]$ configuration within the plateau region shows a progressive fragmentation of the carbon ply followed by dispersed delamination as depicted in Figure 7 for each applied strain. The first knee-point in Figure 6 which is at $1.57 \%$ is where the fragmentation of the carbon ply has been established causing a reduction of stiffness. It is also visible that after $2.45 \%$ strain, the fragmentation has attained saturation and the delamination area did not grow significantly further, which agrees with the second knee point $(2.45 \%)$ in Figure 6. As shown in Figure 7 for the damage at 2.45\% strain, the black-lines correspond to the intact carbon-ply which do not have a sufficient length to carry any more load, as a consequence, the additional load is carried by the glass plies and because there is no more fragmentation or delamination, there is a stress increase as shown in Figure 6

Lack of delamination on the intact carbon-ply (residual black-lines) at 3.05\% strain shown in Figure 7 is possi- bly due to insufficient stress. The shear stresses acting on the intact carbon-ply are less than the yield shear stress and thus the material is undamaged, leaving residual black-lines on the hybrid composite. The bright area which corresponds to the delaminated area is where only frictional shear applies and assumed to carry no loads. This mechanism also applies for the formation of residual blacklines in the $\left[\mathrm{SG}_{1} / \mathrm{TR} 30_{1} / \mathrm{SG}_{1}\right]$ and $\left[\mathrm{SG}_{1} / \mathrm{TR} 30_{2} / \mathrm{SG}_{1}\right]$ hybrid configurations.

As shown in Figure 6, after the specimen is immediately reloaded from zero load, there is a linear elastic behaviour followed by a non-linear behaviour with a knee-point marking the transition. This knee-point is due to fragmentation in the carbon ply. Further fragmentation from the knee-point to the applied peak strain can be attributed to the failure of further weak carbon clusters [43]. When the carbon ply had already fractured across the width as shown in Figure 7, the high interlaminar shear stress which developed between the glass and the fractured carbon ply caused delamination between those plies.

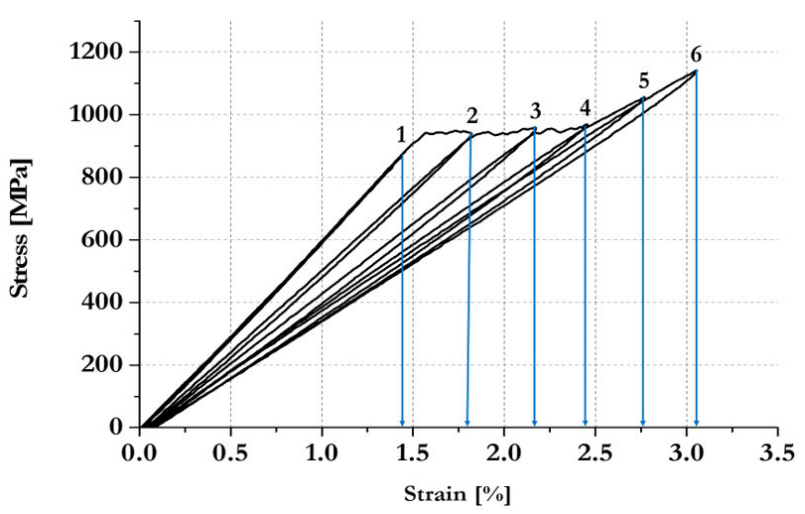

Figure 6. Typical cyclic stress-strain curve for $\left[\mathrm{SG}_{1} / \mathrm{MR} 40_{1} / \mathrm{SG}_{1}\right]$ 


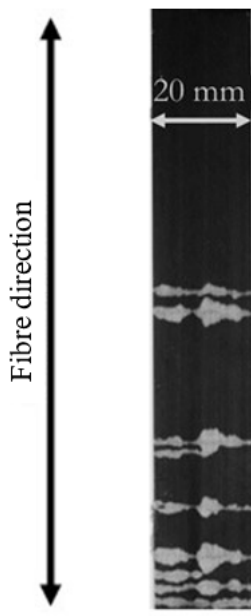

Strain:

$1.82 \%$

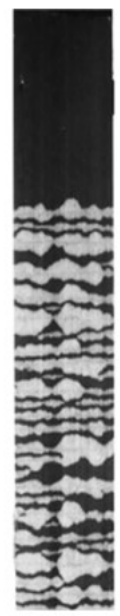

$2.17 \%$

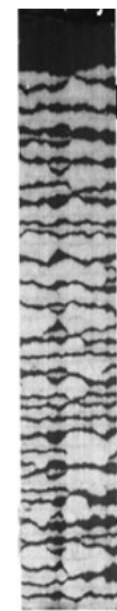

$2.40 \%$

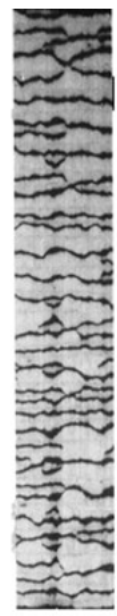

$2.45 \%$

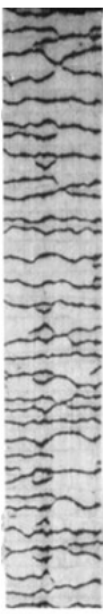

$2.77 \%$

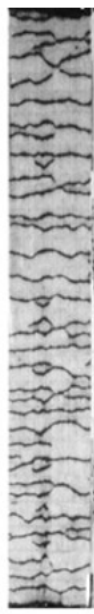

$3.05 \%$

Figure 7. Typical damage development at each strain for $\left[\mathrm{SG}_{1} / \mathrm{MR}_{4} 0_{1} / \mathrm{SG}_{1}\right]$ hybrid.

As the damage progresses, the hybrid loses its stiffness gradually due to fragmentation and stable delamination. There is also a small amount of hysteresis which is believed to be due to reversed high interlaminar shear stresses in the regions around the carbon ply fractures. Due to the compressive stresses around the fracture tip, friction can also apply some interlaminar shear stresses to the intact carbon ply [44]. The high shear stresses between the carbon and glass plies cause the matrix to deform, leaving a residual strain at zero load for all three hybrid configurations. Another possible explanation for the existence of residual strain is due to the accumulation of debris between the open cracks preventing the surface cracks to return to its original state when unloaded. It is also worth mentioning that all the hybrid configurations mentioned in this work experience vertical ply splitting from the edge as shown in the damage mechanism at $3.05 \%$ applied strain in Figure 7. It was also observed that residual bonding between the glass and carbon plies still exists at the final peak strain of 3.05\% as shown in Figure 7. in the form of black-lines running perpendicular to the specimen's length which means that the hybrid had not totally delaminated. To quantify the stiffness loss due to damage growth, the secant modulus for all the UD thinply hybrid composites was evaluated at each reloading step between $0 \mathrm{MPa}$ and $600 \mathrm{MPa}$ as shown schematically in Figure 8. This value was chosen as it is in the elastic region before any further damage takes place. The same method was also used to measure the initial modulus of the $\left[\mathrm{SG}_{1} / \mathrm{TR} 0_{1} / \mathrm{SG}_{1}\right]$ and $\left[\mathrm{SG}_{1} / \mathrm{TR} 30_{2} / \mathrm{SG}_{1}\right]$ hybrid composites.

Stiffness loss as a function of applied peak strain for $\left[\mathrm{SG}_{1} / \mathrm{MR} \mathrm{O}_{1} / \mathrm{SG}_{1}\right]$ hybrid configuration is shown in Figure 9, which shows a gradual loss of stiffness due to fragmentation and stable delamination with increasing applied peak strain from $1.82 \%$ to $2.45 \%$, after which the stiffness approaches the expected value with no carbon contribution at higher strain.

After the fragmentation reached saturation at $2.45 \%$ strain, with further cyclic loading, the measured stiffness remains nearly constant up until 3.05\% where the testing was terminated. The stable delamination after fragmentation during quasi-static cyclic loading is due to the low energy release rate of UD thin-ply hybrid composites [23]. The error bar in Figure 9 shows a low coefficient of variation between $1.10 \%$ to $2.40 \%$ which indicates the repeatability of the test series. The initial $\mathrm{E}_{0}$ and expected final stiffness $\mathrm{E}_{f}$ is calculated by using Equation 2 and Equation 3 respectively adopted from the work by Czél et al. [23].

$$
\begin{gathered}
E_{0}=\frac{\left(E_{g}\left(h-t_{c}\right)+E_{c} t_{c}\right)}{h} \\
E_{0}=\frac{\left(E_{g}\left(h-t_{c}\right)\right)}{h}
\end{gathered}
$$

There is agreement between the value of the measured initial stiffness with the theoretical initial stiffness calculated using Equation 2. As already mentioned before, the gradual stiffness loss of the hybrid is due to fragmentation of the carbon ply and stable delamination between the glass and carbon ply. Because each fragmentation is associated with delamination area surrounding it, then it would be interesting to be able to draw a relation between delamination growth and stiffness loss for UD thin-ply hybrid composites under quasi-static cyclic loading as delamination in this type of hybrid is visually observable. To correlate the stiffness loss with subsequent delamination growth during quasi-static cyclic loading, the images taken from the recording video gauge at different peak strain levels were analysed using an in-house developed MATLAB code as explained in Section 2.5. 


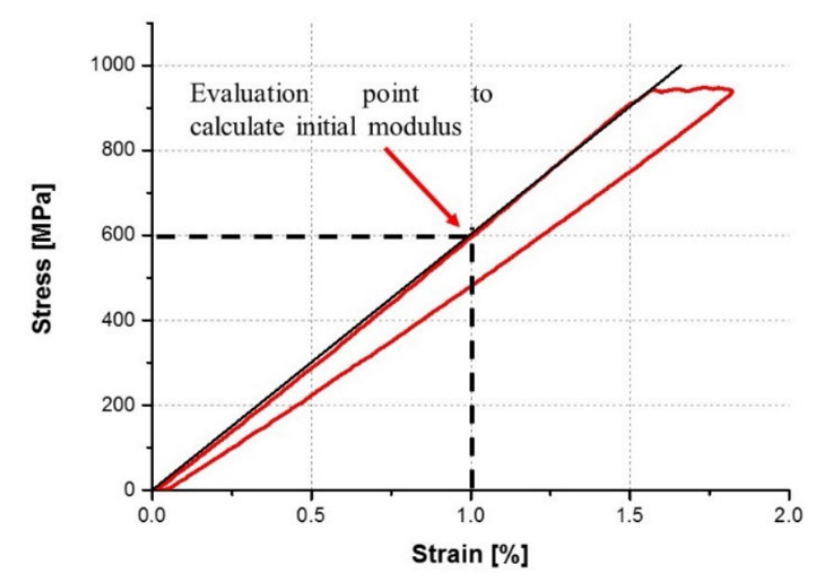

Figure 8. Schematic drawing to define the secant stiffness for all thin-ply hybrid composites.

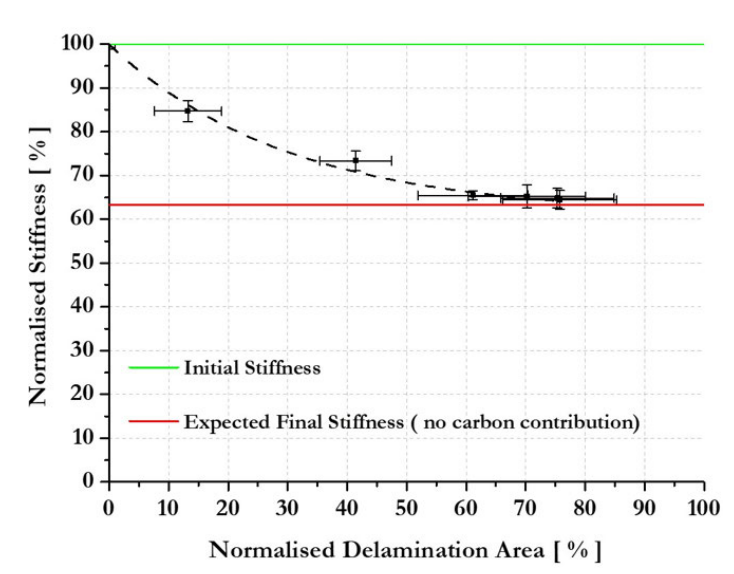

Figure 10. Stiffness loss with growing delaminated area for $\left[\mathrm{SG}_{1} / \mathrm{MR}_{40} / \mathrm{SG}_{1}\right]$ hybrid configuration showing the error bar in both axes.

Figure 10 shows a plot of stiffness loss, as a function of normalised delamination area for the average data of $3\left[\mathrm{SG}_{1} / \mathrm{MR}_{40} \mathrm{O}_{1} / \mathrm{SG}_{1}\right]$ specimens. It is shown in Figure 10 that there is a gradual loss of stiffness from $15 \%$ to $61 \%$ delamination area. This is because multiple fragmentation of carbon ply followed by delamination growing from those fragmentation sites occurred during quasistatic cyclic loading. The normalised stiffness approached saturation when there was no significant additional fragmentation and delamination growth with further loading. As shown in Figure 7, for the damage development from $2.45 \%$ to $3.05 \%$ strain, there is no significant damage growth in the hybrid specimen. At $61 \%$ delamination area, the stiffness loss reaches saturation, and this could be attributed to the high shear stress between the intact carbon and glass ply causing deformation at the interface which hinders load transfer and leads to loss of stiffness contribution. Having a closer examination of the normalised delamination area from $61 \%$ to $75 \%$, it is seen that the normalised stiffness is around $2 \%$ above the expected

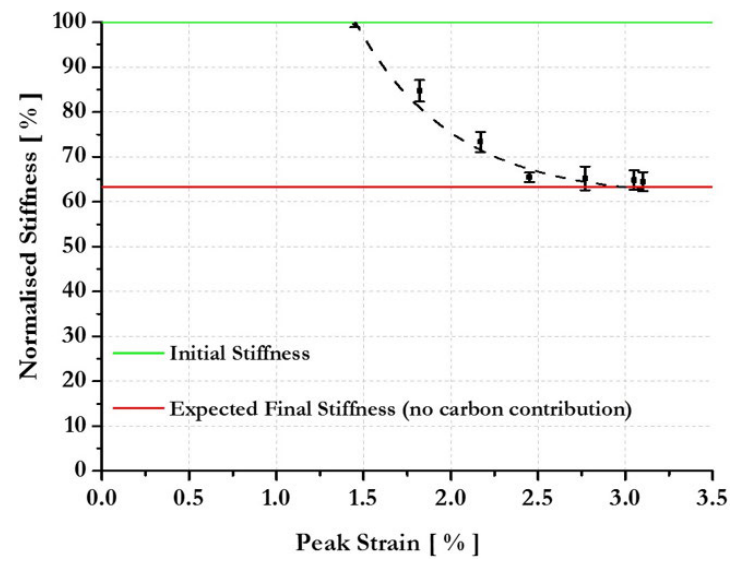

Figure 9. Stiffness loss at each applied peak strain for $\left[\mathrm{SG}_{1} / \mathrm{MR} 40_{1} / \mathrm{SG}_{1}\right]$.

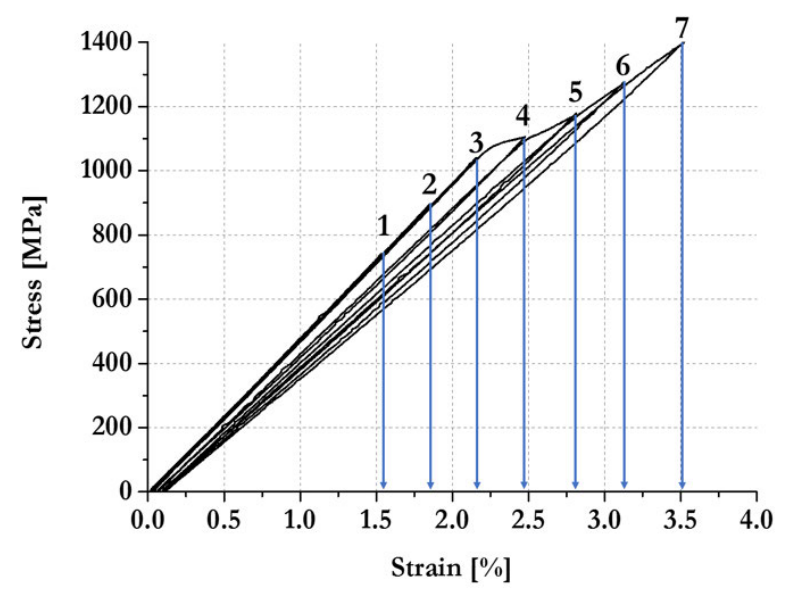

Figure 11. Typical cyclic stress-strain curve for $\left[\mathrm{SG}_{1} / \mathrm{MR} 0_{1} / \mathrm{SG}_{1}\right]$ hybrid.

final stiffness with no carbon contribution. This could mean that the remaining carbon ply shown as black-lines running perpendicular along specimen width in Figure 7 still contributes to minor load carrying capacity. It is also worth mentioning that the error bars shown in Figure 10 for the normalised delamination area, imply significant variation of delamination size between each of the hybrid specimens during the quasi-static cyclic loading.

\subsection{2. $\left[\mathrm{SG}_{1} / \mathrm{TR} 0_{1} / \mathrm{SG}_{1}\right]$ response}

A typical experimental result for the $\left[\mathrm{SG}_{1} / \mathrm{TR} 30_{1} / \mathrm{SG}_{1}\right]$ laminate is presented in Figure 11 In general, there is an initial linear elastic behaviour before the first knee-point followed by non-linear behaviour with a continuous increase of stress at higher strains after the knee-point strain of $2.20 \%$ until $3.50 \%$, with the fragmentation saturating before then. The notation from 1 until 7 in Figure 11 refers to the following peak strains: $1.54 \%, 1.86 \%, 2.17 \%, 2.47 \%, 2.81 \%, 3.13 \%$, $3.52 \%$ respectively. 


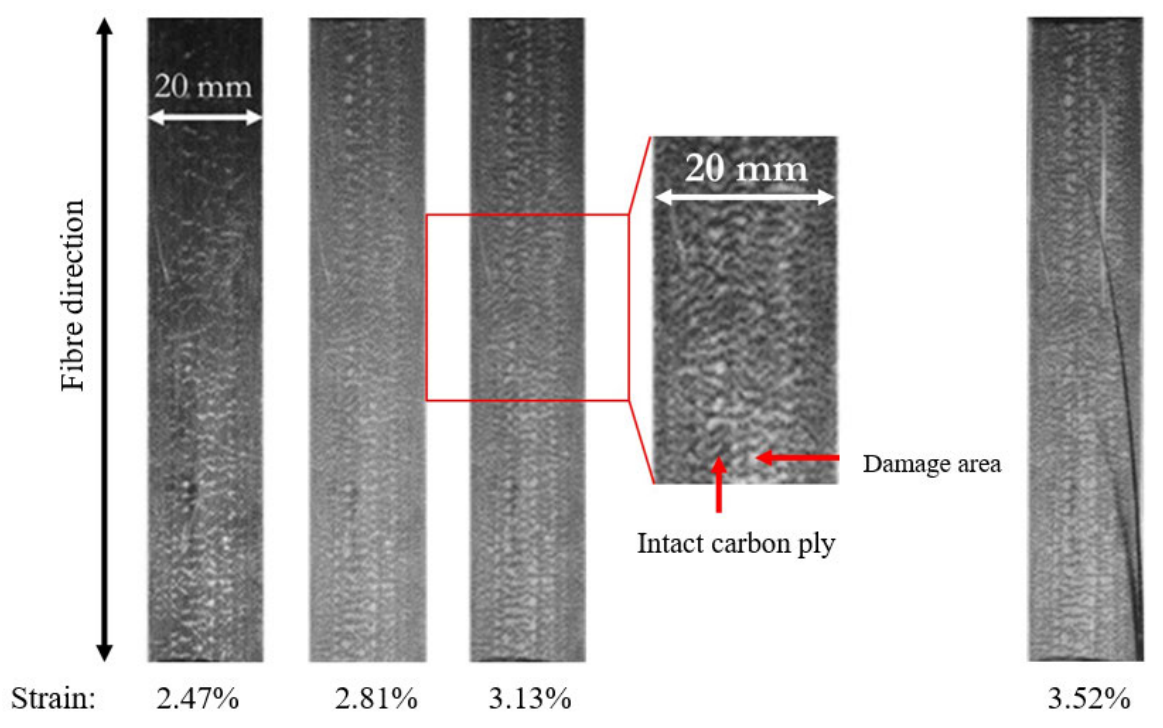

Figure 12. Typical damage pattern at each peak strain for $\left[\mathrm{SG}_{1} / \mathrm{MR} 0_{1} / \mathrm{SG}_{1}\right]$ hybrid.

As shown in Figure 11, initial linear response is shown for the first, second and third loading cycles, because the damage threshold has not been exceeded. For the fourth loading trajectory, it overlaid the rest but went beyond the initial failure strain of the carbon into the increasing region of the stress-strain response. It was observed from this work, that the carbon ply in this hybrid configuration failed at an initial strain of $2.31 \%$ which is higher compared to the $1.90 \%$ strain to failure of the fibre mentioned in Table 1, which means that the outer glass ply provided constraint on further carbon fractures forming a critical broken cluster, thus delaying the initial failure strain of the carbon ply until a higher strain (hybrid effect).

It was observed that beyond the knee-point, there was a dense fragmentation and localised delamination in this hybrid configuration which is due to the shorter process zone around the fragmented ply as shown by Jalalvand et al. [27] in their numerical damage analysis of UD thin carbon/glass hybrid composites. As also explained in [27], in the thinner hybrid laminate, the interface is less damaged so it is possible that the load is being transferred from the intact carbon ply to the glass ply as the fragmentation progresses which means that the $\left[\mathrm{SG}_{1} / \mathrm{TR} 30_{1} / \mathrm{SG}_{1}\right]$ configuration does not delaminate under quasi static cyclic loading and therefore the stress continuously increases beyond the knee-point as shown in Figure 11.

Figure 12 shows the damage pattern at each peak strain for the $\left[\mathrm{SG}_{1} / \mathrm{TR} \mathrm{O}_{1} / \mathrm{SG}_{1}\right]$ configuration, showing a denser fragmentation area compared to the $\left[\mathrm{SG}_{1} / \mathrm{MR}_{4} 0_{1} / \mathrm{SG}_{1}\right]$ specimens in Figure 7 and $\left[\mathrm{SG}_{1} / \mathrm{TR} \mathrm{S}_{2} / \mathrm{SG}_{1}\right]$ in Figure 15 . It should be noted that the criterion for carbon ply failure is the first visible fracture during loading. Within the non-linear region (from $2.47 \%$ to $3.52 \%$ strain), progressive fragmentation of the carbon ply with small fragment spacing took place. It was challenging to observe the growth of fragmentation with subsequent loading strain due to its small scale as indicated in Figure 12.

The increasing stress beyond the knee-point means that after fragmentation of the carbon ply, no real delamination develops as occurred in the $\left[\mathrm{SG}_{1} / \mathrm{MR}_{40} / \mathrm{SG}_{1}\right]$ configuration. This delamination is the reason behind the plateau in the stress-strain curve of $\left[\mathrm{SG}_{1} / \mathrm{MR} 40_{1} / \mathrm{SG}_{1}\right]$ and $\left[\mathrm{SG}_{1} / \mathrm{TR}_{2} 0_{2} / \mathrm{SG}_{1}\right]$ configurations. Dense fragmentation is already shown at $2.47 \%$ strain in Figure 12 and with increasing strain, fragmentation grew continuously. As the damage progressed, a small amount of hysteresis also developed which is attributed to reversed high interlaminar shear stress in the regions around the carbon ply fractures. As explained in Section 3.2.1, this shear stress could be affected by friction between the glass and carbon ply because of the presence of compressive stresses around the crack tip. As depicted in Figure 12, residual bonding between the glass and carbon ply still exists at the final peak strain of $3.52 \%$ in the form of black-lines running perpendicular to the specimens' length. After the fragmentation is saturated at $3.52 \%$ strain, the $\left[\mathrm{SG}_{1} / \mathrm{TR} 0_{1} / \mathrm{SG}_{1}\right]$ hybrid configuration has lost $50 \%$ stiffness contribution from the carbon ply.

Stiffness loss as a function of applied peak strain for $\left[\mathrm{SG}_{1} / \mathrm{TR} 30_{1} / \mathrm{SG}_{1}\right]$ hybrid is shown in Figure 13 , which clearly shows a constant stiffness up to the first three peak strains followed by gradual loss of stiffness from the fourth until the final peak strain due to fragmentation of the UD thin-ply hybrid composites [23]. It is shown in Figure 13 that the final stiffness is substantially higher than the final expected stiffness, which could be attributed to substantial intact area of carbon. The error bar for the normalised stiffness in Figure 13 shows a low coefficient of variation between $0.9 \%$ to $1.50 \%$ which also indicates the consistency of the tests. 


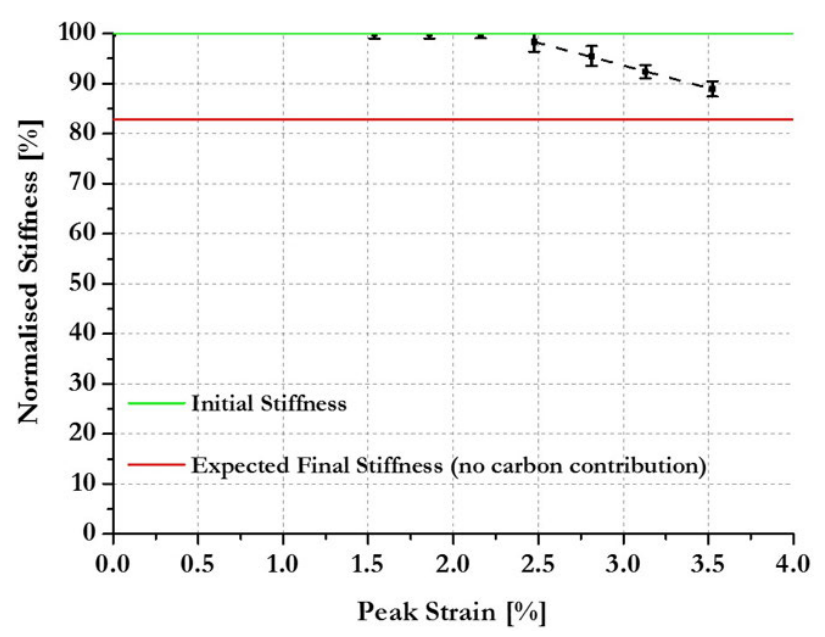

Figure 13. Stiffness loss at each peak strain for $\left[\mathrm{SG}_{1} / \mathrm{MR} 0_{1} / \mathrm{SG}_{1}\right]$ hybrid.

\subsection{3. $\left[\mathrm{SG}_{1} / \mathrm{TR} \mathrm{O}_{2} / \mathrm{SG}_{1}\right]$ response}

A typical experimental result for the $\left[\mathrm{SG}_{1} / \mathrm{TR} 30_{2} / \mathrm{SG}_{1}\right]$ laminate is presented in Figure 14 The cyclic responses show initial linear elastic behaviour before the first knee-point strain of $2.03 \%$ followed by non-linear behaviour after the knee-point strain and slight increase of stress at the final peak strain of 3.13\%.

The notation from 1 until 6 in Figure 14 refers to the following peak strains: $1.61 \%, 1.86 \%, 2.07 \%, 2.35 \%$, $2.67 \%, 3.13 \%$ respectively. Figure 14 shows the initial linear response for the loading and unloading curves for the first and second loading cycles when it was loaded below the damage threshold. The third loading trajectory overlaid the first and second path but went beyond the knee point strain of the hybrid into the plateau region of the stress-strain response. It was observed from this work, that the first visible carbon fracture occurred at a strain of $2.01 \%$ which is higher compared to the failure strain of TR30 fibre mentioned in Table 1. This hybrid effect is lower than that of the $\left[\mathrm{SG}_{1} / \mathrm{TR} 30_{1} / \mathrm{SG}_{1}\right]$ laminate because of the higher ply thickness which meant that the weak clusters in the $\left[\mathrm{SG}_{1} / \mathrm{TR}_{2} \mathrm{O}_{2} / \mathrm{SG}_{1}\right]$ laminate were able to grow into macroscopic fractures at lower strain due to less restriction on forming clusters of broken fibres. Because the weak clusters have more surrounding carbon fibre, once a fibre breaks, it would more easily propagate, thus producing failure at a lower strain.

Within the plateau region, progressive fragmentation of the carbon ply followed by dispersed delamination occurred as shown in Figure 15, a typical damage mechanism for $\left[\mathrm{SG}_{1} / \mathrm{TR}_{2} \mathrm{O}_{2} / \mathrm{SG}_{1}\right]$ hybrid configuration. It is shown in Figure 15, that damage development took the form of carbon ply fragmentation and substantial delamination growth around the fractures at each loading cycle in contrast to the hybrid with single TR30 carbon ply, where

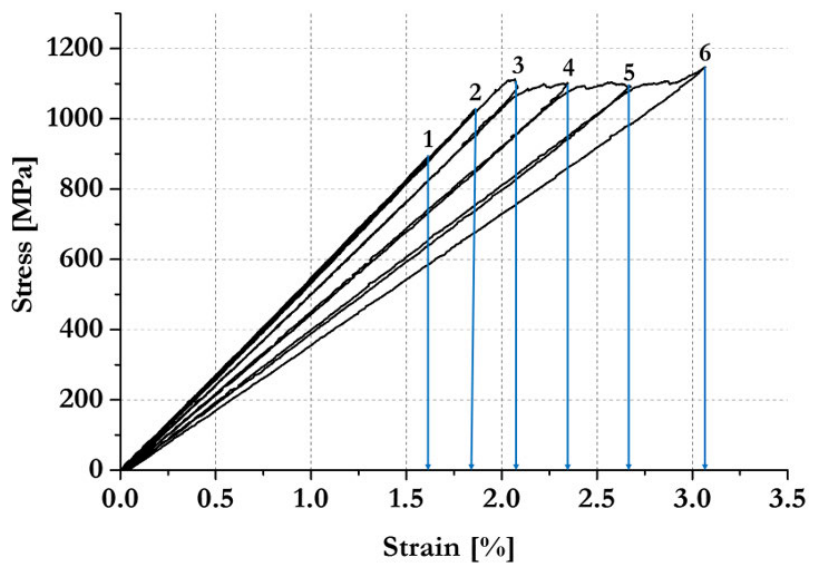

Figure 14. Typical cyclic stress-strain curve for $\left[\mathrm{SG}_{1} / \mathrm{MR} 30_{2} / \mathrm{SG}_{1}\right]$.

the fragmentation pattern was significantly denser, and delamination was limited. The damage pattern at $2.07 \%$ strain shows a different type of damage growth. The red circle shows a short fibre fracture and smaller average delaminated area compared to the delaminated area shown by the blue circle. The fibre fracture shown by the blue circle was able to extend across the whole width because some individual fibres have failed at those locations and developed into clusters of broken weak fibres via matrix damage or local debonding [45]. The different fracture length across the width shown by the red and blue circles also indicates the strength variability within the carbon fibre. The larger average delaminated area shown by the blue circle indicates a locally thicker carbon ply compared to the area shown by the red circle. The thicker carbon ply will provide enough energy to propagate the delamination further after the carbon fibre fractures.

When the carbon ply is fully fragmented at 3.13\% strain as shown in Figure 15, the additional load is taken by the glass ply and the stress starts to increase at $3.13 \%$ as shown in Figure 14. Because of the compressive stress around the crack tip, friction between plies causes a small amount of hysteresis for the $\left[\mathrm{SG}_{1} / \mathrm{TR} 3 \mathrm{O}_{2} / \mathrm{SG}_{1}\right]$ configuration. Extensive vertical ply splitting from the edge as shown in Figure 15 occurred, causing the final stiffness to go insignificantly below its expected final value without any carbon contribution, as shown in Figure 16. The black-lines running perpendicular to the specimen shown in Figure 15 are areas of residual bonding between the glass and carbon ply which shows that this hybrid specimen is not fully delaminated and the carbon was still able to carry some load. If there was no vertical ply splitting, the final stiffness of $\left[\mathrm{SG}_{1} / \mathrm{TR} 3 \mathrm{O}_{2} / \mathrm{SG}_{1}\right]$ configuration should not the reach the expected final stiffness line at all because the residual intact carbon-ply was able to carry minor load. 


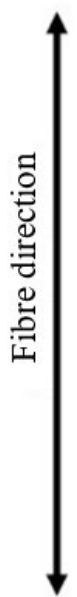

Strain:

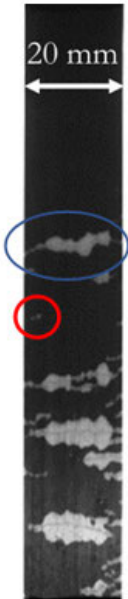

$2.07 \%$

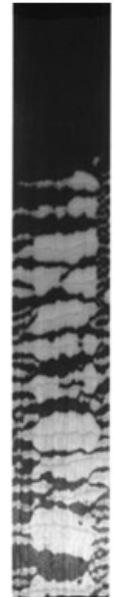

$2.35 \%$

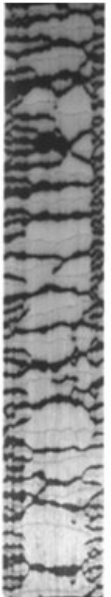

$2.67 \%$

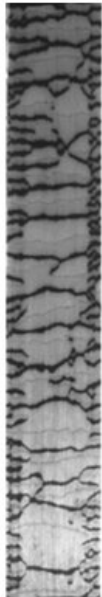

$3.13 \%$

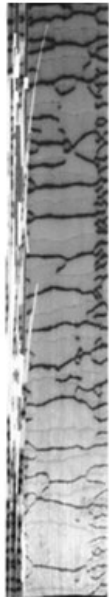

$3.50 \%$

Figure 15. Damage pattern at each peak strain for $\left[\mathrm{SG}_{1} / \mathrm{MR}_{2} \mathrm{O}_{2} / \mathrm{SG}_{1}\right]$ hybrid.

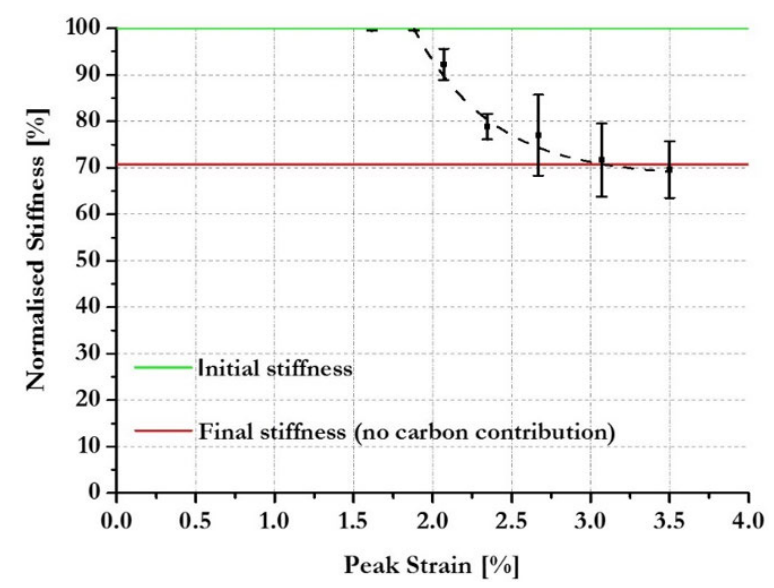

Figure 16. Stiffness loss at each applied peak strain for $\left[\mathrm{SG}_{1} / \mathrm{MR} 0_{2} / \mathrm{SG}_{1}\right]$.

Stiffness loss as a function of applied peak strain is shown in Figure 16, which shows a gradual stiffness loss with increasing fragmentation and stable delamination [23] approaching the expected value with no carbon contribution at higher strain. The error bars in Figure 16 show a coefficient of variation between $0.40 \%$ to $7.80 \%$ which indicates the consistency of specimen responses, but it is still higher compared to the two previous hybrid laminates. This is due the susceptibility of some of the $\left[\mathrm{SG}_{1} / \mathrm{TR}_{3} \mathrm{~T}_{2} / \mathrm{SG}_{1}\right]$ specimens to vertical ply splitting at higher strains.

Figure 17 shows a plot of stiffness loss, as a function of normalised delamination area for the averaged measurements of three specimens. It is shown in Figure 17 that there is a gradual loss of stiffness from $12 \%$ to $68 \%$ delamination area with the final normalised stiffness going insignificantly below the expected final stiffness.

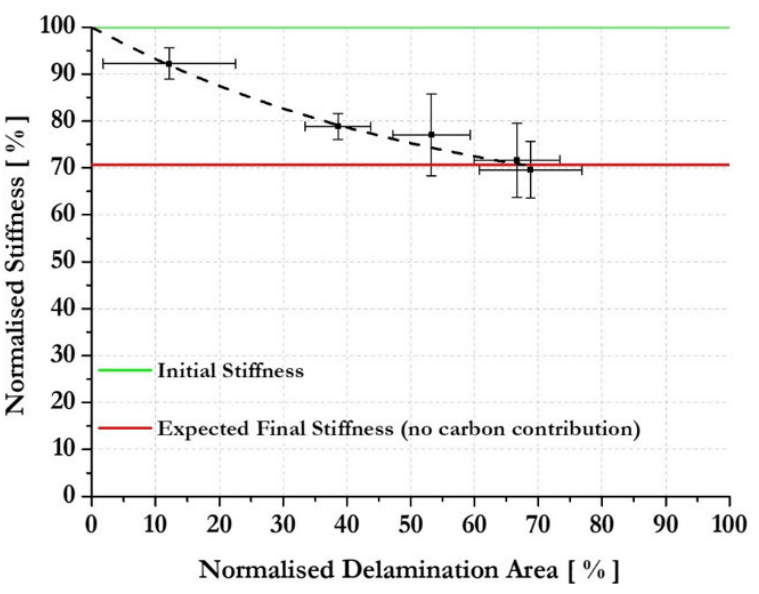

Figure 17. Stiffness loss with growing delaminated area for $\left[\mathrm{SG}_{1} / \mathrm{MR} \mathrm{S}_{2} / \mathrm{SG}_{1}\right]$.

\section{Conclusions}

The following conclusions were drawn from the study of continuous glass/carbon hybrid laminates under quasi-static cyclic loading. The quasi-static response of the hybrids is affected by the carbon/glass volume ratio, the carbon ply thickness and the carbon properties (modulus, strain to failure). There is a small amount of hysteresis and residual strain, which can be attributed to two reasons: the significant reversed shear stress at the ply interfaces near the ends of the several delaminated regions of the fragmented hybrid deforming the matrix and the accumulation of debris between the open cracks preventing the surface cracks to return to its original state when unloaded. The response of the UD thin-ply hybrid laminate is considered pseudo-ductile because the damage in the form of ply fragmentation and localized delamination, leads to gradual loss of stiffness [46]. The extent of stiffness loss is governed by the density of fragmentation and the corresponding delamination pattern. 


\section{Acknowledgments}

This work was funded under the UK Engineering and Physical Sciences Research Council Programme Grant EP/I02946X/1 on High Performance Ductile Composite Technology in collaboration with Imperial College, London. Putu Suwarta acknowledges The Directorate General of Higher Education of the Ministry of Education and Culture of the Republic of Indonesia (DIKTI) for funding through the DIKTI scholarship. The authors acknowledge Hexcel Corporation and SK Chemical for supplying materials for this research. Supporting data can be requested from the corresponding author.

\section{References}

[1] P. D. Mangalgiri, "Composite materials for aerospace applications," Bulletin of Materials Science, vol. 22, pp. 657-664, May 1999.

[2] G. Savage, "Composite materials technology in formula 1 motor racing," Honda Racing F1 Team, vol. 1, pp. 109-139, July 2008.

[3] D. S. S. Swanek and J. Carey, "Braided composite materials for the production of lightweight, high rigidity golf shafts," Sports Engineering, vol. 10, pp. 195-208, Dec 2007.

[4] L. Mishnaevsky, K. Branner, H. N. Petersen, J. Beauson, M. McGugan, and B. F. Sørensen, "Materials for wind turbine blades: An overview," Materials, vol. 10, no. 11, pp. 1-24, 2017.

[5] K. Edwards, "An overview of the technology of fibrereinforced plastics for design purposes," Materials Design, vol. 19, no. 1, pp. 1-10, 1998.

[6] K. W. Gan, M. R. Wisnom, and S. R. Hallett, "Effect of high through-thickness compressive stress on fibre direction tensile strength of carbon/epoxy composite laminates," Composites Science and Technology, vol. 90, pp. 1-8, 2014.

[7] S. Sutikno, R. F. Rizal, and A. Safaat, "Numerical study of epoxy-ramie fiber composite as a type iv ballistic resistant material," JMES The International Journal of Mechanical Engineering and Sciences, vol. 5, no. 1, pp. 30-38, 2021.

[8] K. Allaer, I. De Baere, P. Lava, W. Van Paepegem, and J. Degrieck, "On the in-plane mechanical properties of stainless steel fibre reinforced ductile composites," Composites Science and Technology, vol. 100, pp. 3443, 2014.

[9] M. Callens, L. Gorbatikh, and I. Verpoest, "Ductile steel fibre composites with brittle and ductile matrices," Composites Part A: Applied Science and Manufacturing, vol. 61, pp. 235-244, 2014.
[10] M. G. Callens, L. Gorbatikh, E. Bertels, B. Goderis, M. Smet, and I. Verpoest, "Tensile behaviour of stainless steel fibre/epoxy composites with modified adhesion," Composites Part A: Applied Science and Manufacturing, vol. 69, pp. 208-218, 2015.

[11] M. G. Callens, P. De Cuyper, L. Gorbatikh, and I. Verpoest, "Effect of fibre architecture on the tensile and impact behaviour of ductile stainless steel fibre polypropylene composites," Composite Structures, vol. 119, pp. 528-533, 2015.

[12] Y. Swolfs, P. De Cuyper, M. Callens, I. Verpoest, and L. Gorbatikh, "Hybridisation of two ductile materials - steel fibre and self-reinforced polypropylene composites," Composites Part A: Applied Science and Manufacturing, vol. 100, pp. 48-54, 2017.

[13] G. Marom, S. Fischer, F. R. Tuler, and H. D. Wagner, "Hybrid effects in composites: conditions for positive or negative effects versus rule-of-mixtures behaviour," Journal of Materials Science, vol. 13, pp. 1419-1426, Jul 1978.

[14] N. Svensson, R. Shishoo, and M. Gilchrist, "Thermoplastic," Journal of Thermoplastic Composite Materials, vol. 11, pp. 22-50, Jan. 1998.

[15] H. Diao, A. Bismarck, P. Robinson, and M. Wisnom, "Pseudo-ductile behaviour of unidirectional fibre reinforced polyamide-12 composite by intra-tow hybridization," in Proceedings of ECCM, vol. 15, 2012.

[16] T. Hayashi, "Development of new material properties by hybrid composition (1st report)," Fukugo Zairyo (composite materials), vol. 1, pp. 18-20, 1972.

[17] T. Hayashi, "Development of new material properties by hybrid composition (2nd report)," Fukugo Zairyo (composite materials), vol. 1, pp. 21-25, 1972.

[18] A. Bunsell and B. Harris, "Hybrid carbon and glass fibre composites," Composites, vol. 5, no. 4, pp. 157164, 1974.

[19] P. W. Manders and M. Bader, "The strength of hybrid glass/carbon fibre composites," Journal of materials science, vol. 16, no. 8, pp. 2246-2256, 1981.

[20] K. K. S. Sihn, R. Y. Kim and S. W. Tsai, "Experimental studies of thin-ply laminated composites," Composite Science Technology, vol. 55, no. 643, pp. 388-395, 2007.

[21] T. Yokozeki, A. Kuroda, A. Yoshimura, T. Ogasawara, and T. Aoki, "Damage characterization in thinply composite laminates under out-of-plane transverse loadings," Composite Structures, vol. 93, no. 1, pp. 49-57, 2010. 
[22] H. Saito, M. Morita, K. Kawabe, M. Kanesaki, H. Takeuchi, M. Tanaka, and I. Kimpara, "Effect of ply-thickness on impact damage morphology in cfrp laminates," Journal of Reinforced Plastics and Composites, vol. 30, no. 13, pp. 1097-1106, 2011.

[23] G. Czél and M. Wisnom, "Demonstration of pseudoductility in high performance glass/epoxy composites by hybridisation with thin-ply carbon prepreg," Composites Part A: Applied Science and Manufacturing, vol. 52, pp. 23-30, 2013.

[24] G. Czél, M. Jalalvand, and M. R. Wisnom, "Design and characterisation of advanced pseudo-ductile unidirectional thin-ply carbon/epoxy-glass/epoxy hybrid composites," Composite Structures, vol. 143, pp. 362-370, 2016.

[25] M. Fotouhi, P. Suwarta, M. Jalalvand, G. Czel, and M. R. Wisnom, "Detection of fibre fracture and ply fragmentation in thin-ply ud carbon/glass hybrid laminates using acoustic emission," Composites Part A: Applied Science and Manufacturing, vol. 86, pp. 6676, 2016.

[26] P. Suwarta, M. Fotouhi, G. Czél, M. Longana, and M. R. Wisnom, "Fatigue behaviour of pseudo-ductile unidirectional thin-ply carbon/epoxy-glass/epoxy hybrid composites," Composite Structures, vol. 224, p. 110996, 2019.

[27] M. Jalalvand, G. Czél, and M. R. Wisnom, "Numerical modelling of the damage modes in ud thin carbon/glass hybrid laminates," Composites Science and Technology, vol. 94, pp. 39-47, 2014.

[28] M. Jalalvand, G. Czél, and M. R. Wisnom, "Damage analysis of pseudo-ductile thin-ply ud hybrid composites - a new analytical method," Composites Part A: Applied Science and Manufacturing, vol. 69, pp. 83-93, 2015.

[29] M. Jalalvand, G. Czél, and M. R. Wisnom, "Parametric study of failure mechanisms and optimal configurations of pseudo-ductile thin-ply ud hybrid composites," Composites Part A: Applied Science and Manufacturing, vol. 74, pp. 123-131, 2015.

[30] J. Keer, "Behaviour of cracked fibre composites under limited cyclic loading," International Journal of Cement Composites and Lightweight Concrete, vol. 3, no. 3, pp. 179-186, 1981.

[31] J. Keer, "Influence of fibre characteristics on polyolefin reinforced composites under limited cyclic loading," International Journal of Cement Composites and Lightweight Concrete, vol. 9, no. 3, pp. 145-156, 1987.

[32] N. Takeda and S. Ogihara, "Initiation and growth of delamination from the tips of transverse cracks in cfrp cross-ply laminates," Composites Science and Technology, vol. 52, no. 3, pp. 309-318, 1994.

[33] M. R. Wisnom, J. Fuller, P. Suwarta, and G. Czél, "Repeated tensile loading of thin-ply pseudo-ductile laminates," pp. 2-9, 2015.

[34] J. Aveston and A. Kelly, "Theory of multiple fracture of fibrous composites," Journal of Materials Science, vol. 8, pp. 352-362, Mar 1973.

[35] J. Fuller, Pseudo-ductility of thin ply angle-ply laminates. PhD thesis, University of Bristol, 2015.

[36] G. Czél, M. Jalalvand, and M. R. Wisnom, "Hybrid specimens eliminating stress concentrations in tensile and compressive testing of unidirectional composites," Composites Part A: Applied Science and Manufacturing, vol. 91, pp. 436-447, 2016. CompTest 2015.

[37] G. Czél, M. Jalalvand, and M. R. Wisnom, "Design and characterisation of advanced pseudo-ductile unidirectional thin-ply carbon/epoxy-glass/epoxy hybrid composites," Composite Structures, vol. 143, pp. 362-370, 2016.

[38] Mitsubishi-Rayon, "Mitsubishi-rayon. mitsubishi rayon pyro 1 carbon fibres."

[39] SKChemicals, "Skchemicals. standard resin: K 50."

[40] O. Corning, "Ocv reinforcements flite strand s -glass."

[41] M. Wisnom, G. Czél, Y. Swolfs, M. Jalalvand, L. Gorbatikh, and I. Verpoest, "Hybrid effects in thin ply carbon/glass unidirectional laminates: Accurate experimental determination and prediction," Composites Part A: Applied Science and Manufacturing, vol. 88, pp. 131-139, 2016.

[42] B. W. Rosen, "Tensile failure of fibrous composites," AIAA Journal, vol. 2, no. 11, pp. 1985-1991, 1964.

[43] F. Taheri, "18 - advanced fiber-reinforced polymer (frp) composites for the manufacture and rehabilitation of pipes and tanks in the oil and gas industry," in Advanced Fibre-Reinforced Polymer (FRP) Composites for Structural Applications (J. Bai, ed.), Woodhead Publishing Series in Civil and Structural Engineering, pp. 662-704, Woodhead Publishing, 2013.

[44] M. Jalalvand, G. Czél, J. D. Fuller, M. R. Wisnom, L. P. Canal, C. D. González, and J. LLorca, "Energy dissipation during delamination in composite materials - an experimental assessment of the cohesive law and the stress-strain field ahead of a crack tip," Composites Science and Technology, vol. 134, pp. 115-124, 2016. 
[45] E. Gamstedt and R. Talreja, "Fatigue damage mechanisms in unidirectional carbon-fibre-reinforced plastics," Journal of materials science, vol. 34, no. 11, pp. 2535-2546, 1999.
[46] M. R. Wisnom, J. Fuller, P. Suwarta, and G. Czél, "Repeated tensile loading of thin-ply pseudo-ductile laminates," 2015. 